$2-1-93$

精神薄弱児における断続語音倹查

大和田健次郎·中西靖子(東京学芸大)

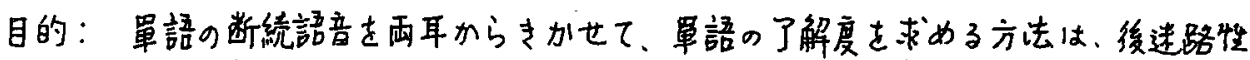

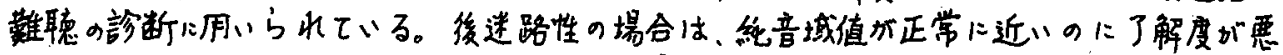
い。これはことばの了解の障害であろうが、障害でなくてて、ことばてよく知らなりれば

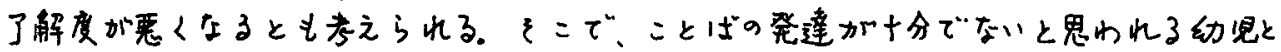
精薄览について断绕諎栓查を行なった。

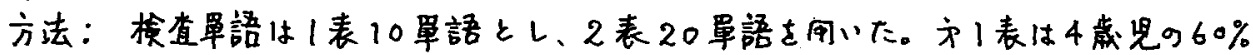

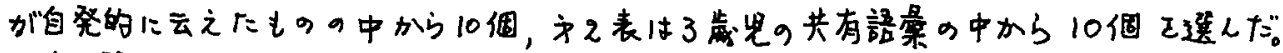

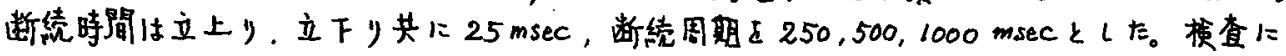

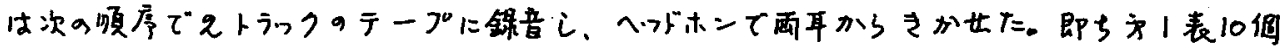

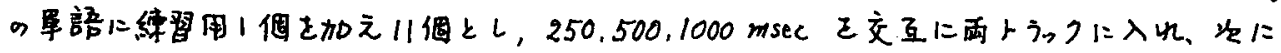

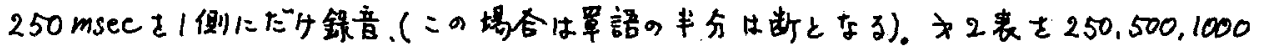

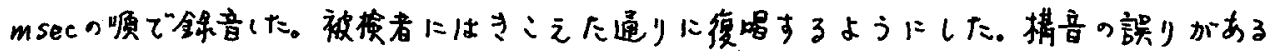
ので、禹表共に绘カードて用いて発者を確かめた。

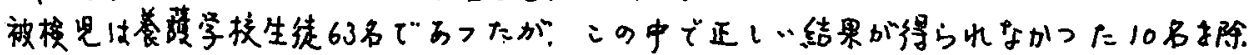

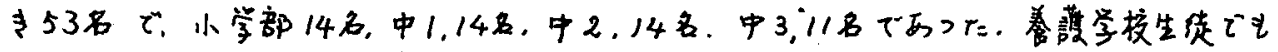

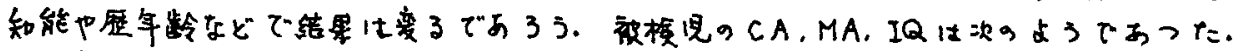

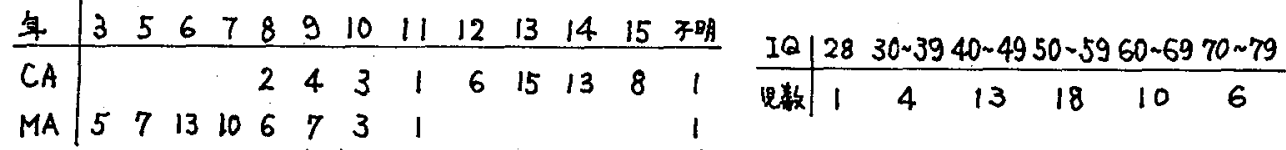

IQ9测定は落学挍で行なかれた结果支借用したものである。

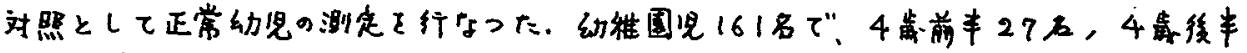

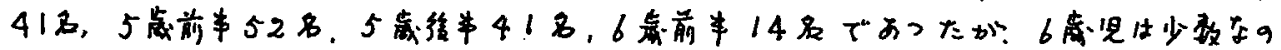
で除外してある。

使用した棓表は音能教などー定していない。次のようである。

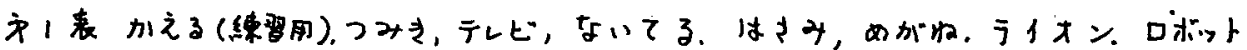
ずばん、でんめ。おちゅわん。

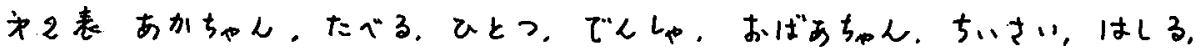

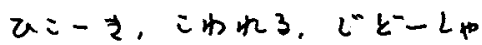

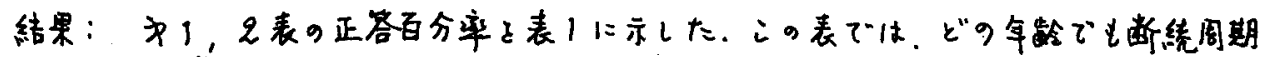

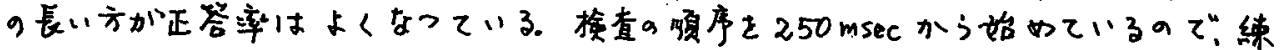

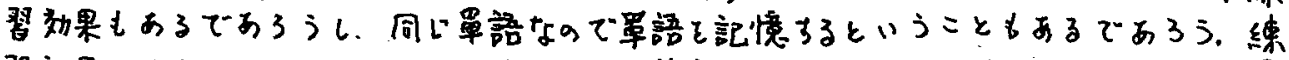

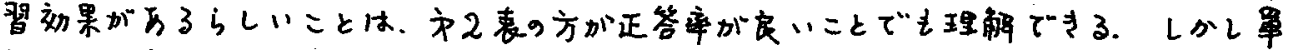

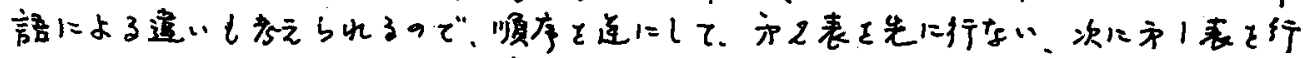

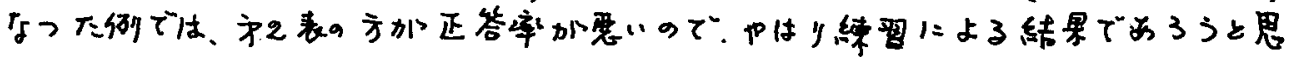
われる。 
表1. 断绕語昔正荅百分率

\begin{tabular}{|c|c|c|c|c|c|c|c|c|c|c|}
\hline \multirow{2}{*}{ 断绕 } & \multicolumn{2}{|c|}{ |4 肯前半(27) } & \multicolumn{2}{|c|}{ | 4 量往半 (41) } & \multicolumn{2}{|c|}{ |5前前半 (52) } & \multicolumn{2}{|c|}{5 歳情半 (41) } & \multicolumn{2}{|c|}{ 美学学校生(53) } \\
\hline & 牙表 & 汸2表 & 文表 & 市2表 & 文哀 & ॠ2表 & 文!表 & 內2表 & 方表 & 才2表 \\
\hline 250 浊 & 33.3 & 46,3 & 40.5 & 51.0 & 42.3 & 57.5 & 53.4 & 63.7 & 59.8 & 50.6 \\
\hline 000 (12 & 56.0 & 60.4 & 64.6 & 64.4 & 65.0 & 71.2 & 80.7 & 77.1 & 79.8 & 73.0 \\
\hline 1000 两 & 83.7 & 80.4 & 84.1 & 86.6 & 87.1 & 92.9 & 92.9 & 93.2 & 89.1 & 84.9 \\
\hline 250 & 28.5 & & 39.5 & & 36.7 & & 42.4 & & 58.7 & \\
\hline
\end{tabular}

表中の数字は捈査全军語に対する正容の\%を示す。

表2。內!表，內2表における平均正答数（正常班）

礼表

\begin{tabular}{|c|c|c|c|c|}
\hline & 4藏前 & 4跲嗖 & 5煎 & 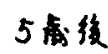 \\
\hline $250^{\mathrm{msec}}$ & 3.3 & 4.0 & 4.2 & 5.3 \\
\hline 500 & 5.6 & 6.5 & 6.7 & 7.3 \\
\hline 1000 & 8.4 & 8.4 & 8.7 & 9.3 \\
\hline & 2.9 & 3.9 & 3.6 & 4.2 \\
\hline
\end{tabular}

內2表

\begin{tabular}{|c|c|c|c|}
\hline 4㤐前 & 4齿:续 & 5 羍前 & 5 点 \\
\hline 4.0 & 5.1 & 5.8 & 6.4 \\
\hline 6.1 & 6.3 & 7.1 & 7.8 \\
\hline 8.0 & 8.7 & 9.3 & 9.3 \\
\hline
\end{tabular}

表了、精薄是におけるIQと正答平均细数

\section{方। 表}

\begin{tabular}{|c|c|c|c|c|c|c|c|c|c|c|c|}
\hline$I Q$ & 304 & 406 & $50 \frac{4}{a}$ & 608 & 70 台 & IQ & 30 台 & $40 \Delta$ & 50 . & $60 \%$ & 70台 \\
\hline $25^{b^{\sec }}$ & 4.8 & 5.3 & 6.1 & 5.6 & 7.7 & & 6.0 & 5.2 & 5.9 & 5.3 & 7.3 \\
\hline 500 & 7.0 & 7.3 & 8.5 & 7.4 & 9.2 & & 6.3 & 7.1 & 7.2 & 7,3 & 9.3 \\
\hline 1000 & 8.3 & 8.7 & 9.7 & 8.9 & 9.3 & & 8.5 & 8.2 & 8.2 & 8.6 & 9.5 \\
\hline $250 k$ & 7.0 & 5.0 & 7.0 & 5.4 & 7.3 & & & & & & \\
\hline
\end{tabular}

表4MA E正答平均㑑数（文|表）

\begin{tabular}{l|cccccccc} 
MA & 3 & 5 & 6 & 7 & 8 & 9 & 10 & $11(18)$ \\
\hline 250 & 6.4 & 5.6 & 5.1 & 4.9 & 7.2 & 6.3 & 8.0 & 10 \\
500 & 8.4 & 5.7 & 7.3 & 8.0 & 8.7 & 8.0 & 9.7 & 10 \\
1000 & 7.6 & 9.0 & 8.7 & 9.2 & 9.2 & 9.0 & 9.7 & 9 \\
$250 \mathrm{msec}$ & 2.8 & 5.4 & 5.7 & 6.5 & 5.7 & 6.6 & 8.7 & 5
\end{tabular}

结語: 0 断绕棓音模查9结果 は正常幼坚では正荅百分率が 成人に比i彭い。

2) 精落旧でも正常坚と同样

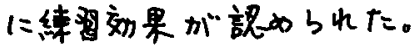
3) 断绕語音正客数は。 IQの增加と共に增した。 4) MAが低いと正管数が

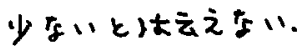

